\title{
The Fractal Characteristics of the River Network in the Landslides Area
}

\author{
Zhi-wang Wang ${ }^{1,2,3, \text { a }}$, Hao Cao ${ }^{1,2,3, b}$ and Fang-fang Zhou ${ }^{1,2,3, c}$ \\ ${ }^{1}$ Changjiang River Scientific Research Institute, Wuhan, China. \\ ${ }^{2}$ Research Center on Water Engineering Safety and Disaster Prevention of the Ministry of Water \\ Resources, Wuhan, China. \\ ${ }^{3}$ Research Center on National Dam Safety Engineering Technology,Wuhan, China. \\ awzwhbwh@126.com, ${ }^{\mathrm{b}}$ insulator625@126.com, ${ }^{\mathrm{T}}$ zhouff5@126.com
}

Keywords: Fractal, River network, Landslide.

Abstract. This paper applies box-counting model to study the fractal characteristics of 17 sub-watersheds in the study area from Badong county to Zigui county in TGP reservoir region. The results indicate that the small watersheds have obvious fractal characteristics and that fractal dimension values of sub-watersheds near the Yangtze River are generally smaller than those of small watersheds far away from the Yangtze River. It shows that the fractal of water system in the study area has obvious spatial differentiation. The relationship between the fractal dimension of topography and landform and the development of landslide is closely related to the erosion of the river. The results show that the fractal model provides powerful tools for quantitative description of the river network and the relationship between the river network and the landslides.

\section{Introduction}

Landslide is a common geological disaster occurring regionally and frequently. It usually produces serious damages to factories, mines, cities and towns, villages, farmlands, transportation, communication, and even blocks rivers and destroys the water conservancy projects. It occurred regionally and frequently in the mountainous areas of China. Therefore, it is of importance and significance to study the landslide so as to improve the landslide prevention and control, and to guarantee the engineering safety and the environmental protection.

The river network is the landscape formed by erosion, transport and accumulation of surface water, and it is also the product of the inside and outside geological effects. The formation and development of the river networks are related to various factors such as climate, stratum lithology and geological structure. The river network has the characteristics of self-similarity and scale-invariance, and has typical fractal characteristics. Therefore, the fractal theory can be used to study its distribution pattern. The landslide is also affected by the climate, topography, geological structure constraints. The study of fractal geometry of the river network can quantitatively compare and analyze the morphological characteristics of the river network and its differences in different regions, and then discuss the relationship between fractal dimension of water system and landslide. This paper uses the box-counting techniques to calculate the fractal dimensions of the river network in the landslides area. The results show that these fractal models provide powerful tools for quantitative description of the river network and the relationship between the river network and the landslides.

\section{Study Area and Data Sets}

Landslide is be prone to occur and to cause natural hazards in the Three Gorges reservoir region, where there have varied topographies, complicated geological structures, and heavy annual rainfall. The landslide hazards often destroyed houses, road and farmlands. So the landslide hazards are the important issue to influence the settlement project, shipping and ecological environment in the Three Gorges reservoir region. It is thus important to study the landslide in the area to reduce the landslide hazards, and to ensure the reservoir safety. 
The study area is located in Hubei Province from Zigui to Badong counties. There are many landslides, for example, Xintan landslide, Huangtupo landslide and Huanglashi landslide, which are usually located in the section with "hard" rock and "soft" rock jointly and along the bank of the river. The landslides often cause serious damage to the area. For instance, the Huangtupo landslide forced the new town of Badong county to be relocated to Xirangpo, about $6 \mathrm{~km}$ to the west of Huangtupo. Another recent landslide, on 3rd March 2002, moved more than 20 million cubic metres of debris down slope, threatening the new town of Wushan county(Wu et al. 2001).

The main data for this study is the 1:50,000 scale digitized geological map and DEM, from which the river network and the sub-basins were obtained.

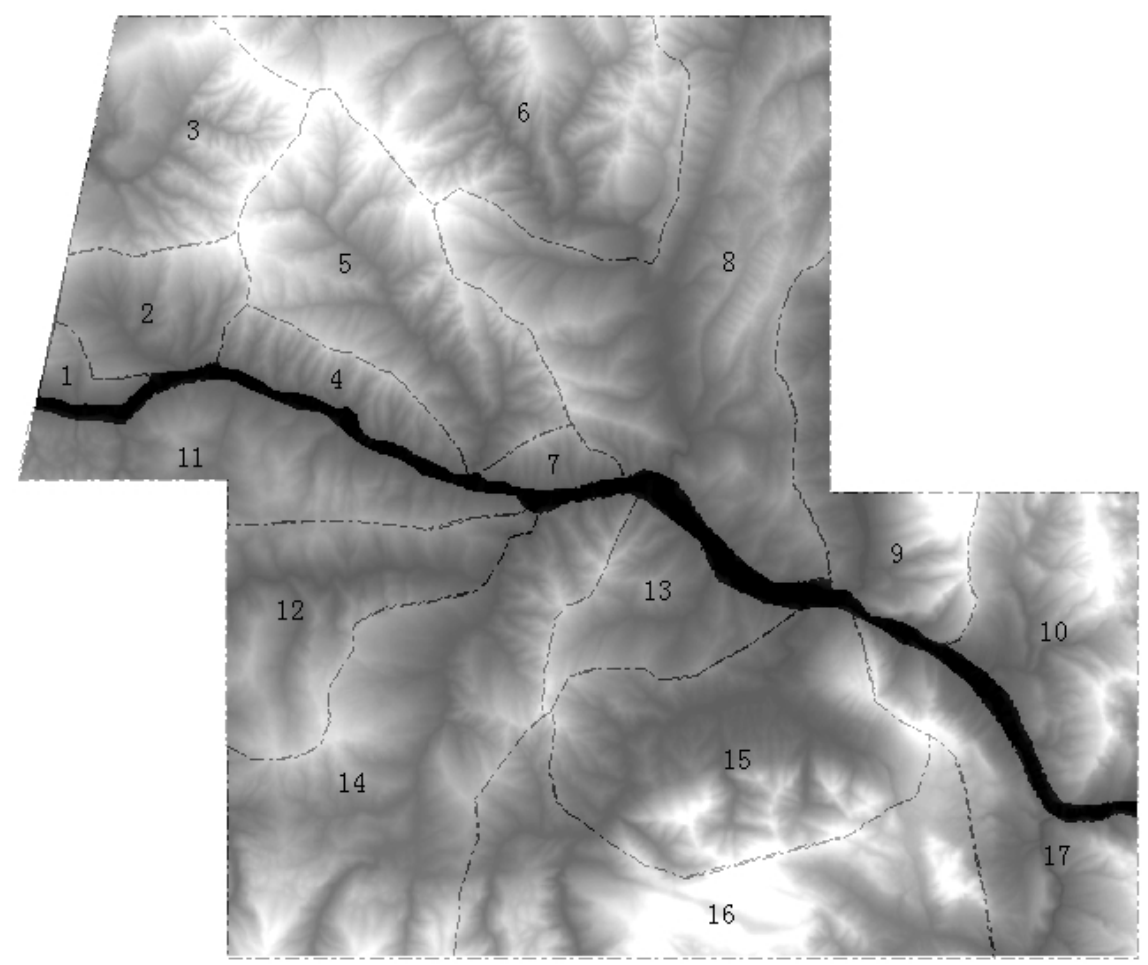

Fig. 1 DEM and the sub-basins of the study area

\section{The Box-counting Method}

There are many methods of measuring and calculating the fractal dimension. For a certain area of statistical measurement, the box-counting method is simple, objective and practical and thus it is now widely used.The box-counting method is a convenient and objective fractal dimension method (Falconer., 1990). If the study area is divided into a number of squares with the length of $\varepsilon$ in the selected area, the number of lattices of the geometry is determined to be $\mathrm{N}$, Then change $\varepsilon$ to find the corresponding $\mathrm{N}(\varepsilon)$, and so on, and finally find the fractal dimension $\mathrm{D}$ by the following formula.

$$
D=-\lim _{\varepsilon \rightarrow 0} \log N(\varepsilon) / \log \varepsilon
$$

\section{Results and Discussion}

The box-counting method was used to calculate and analyze the water system in 17 small watersheds in the study area. From $\log N(\varepsilon) \sim \log (\varepsilon) \operatorname{logarithmic}$ curve(Figure 2), it can be seen that $\operatorname{LogN}(\varepsilon)$ and $\log (\varepsilon)$ have a clear linear relationship and a high degree of straight line fitting. The results indicate that the sub-watersheds have obvious fractal characteristics. It can be seen from the distribution of fractal values of different watersheds in the study area (Figure 3) that fractal dimension values of small watersheds near the Yangtze River are generally smaller than those of small watersheds far away from the Yangtze River, It shows that the fractal of water system in the study area has obvious spatial differentiation. The relationship between the fractal dimension of topography and landform and the 
development of landslide is closely related to the erosion of the river. And the landslides in the study area are mostly located along the banks of Yangtze river. So the erosion of the river is obviously related to the fractal dimension of topography and landform and the development of landslide. The results show that these fractal models provide powerful tools for quantitative description of the river network and the relationship between the river network and the landslides.
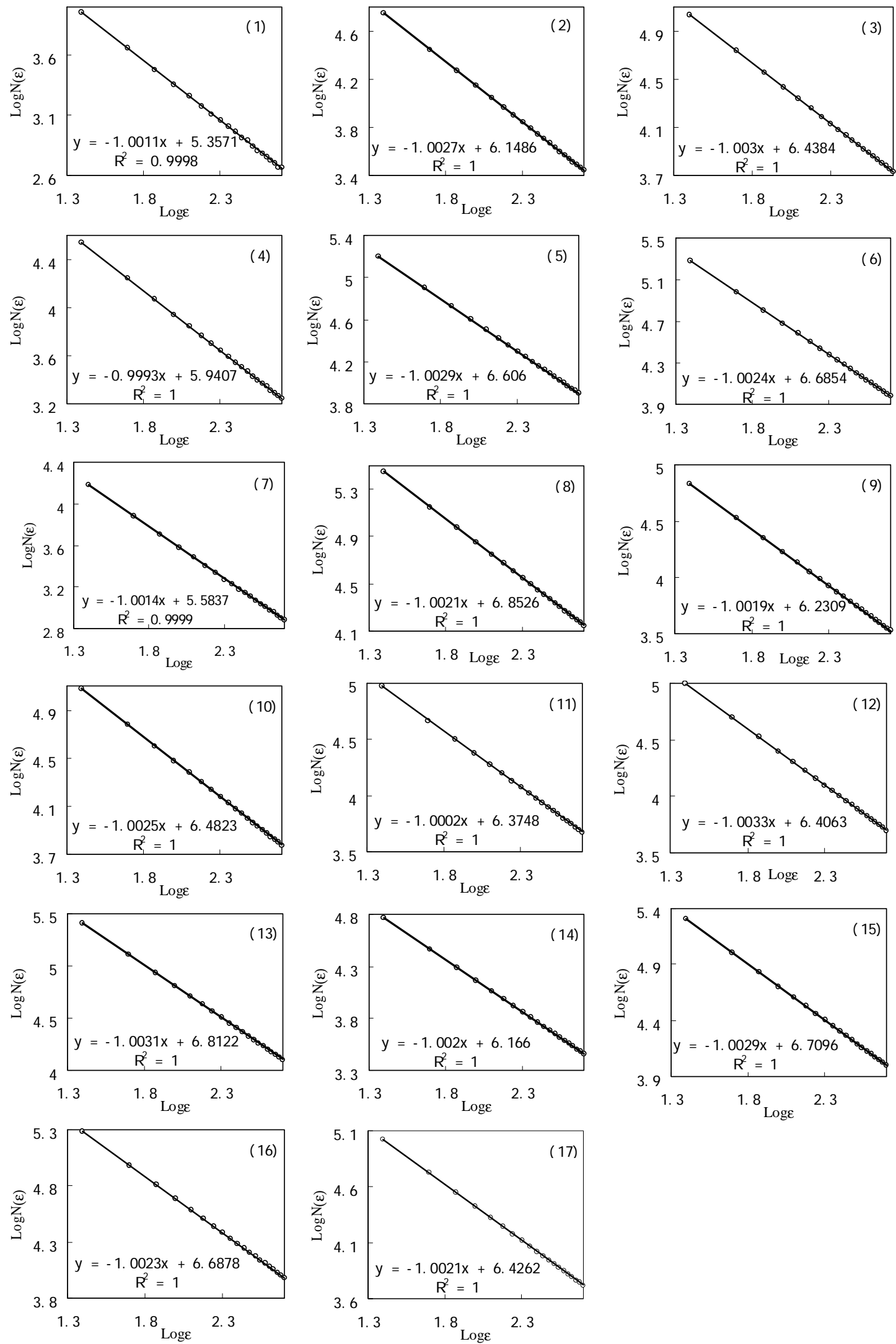

Fig. 2 The fractral dimensions plot of the river network in the sub-basins of the study area 


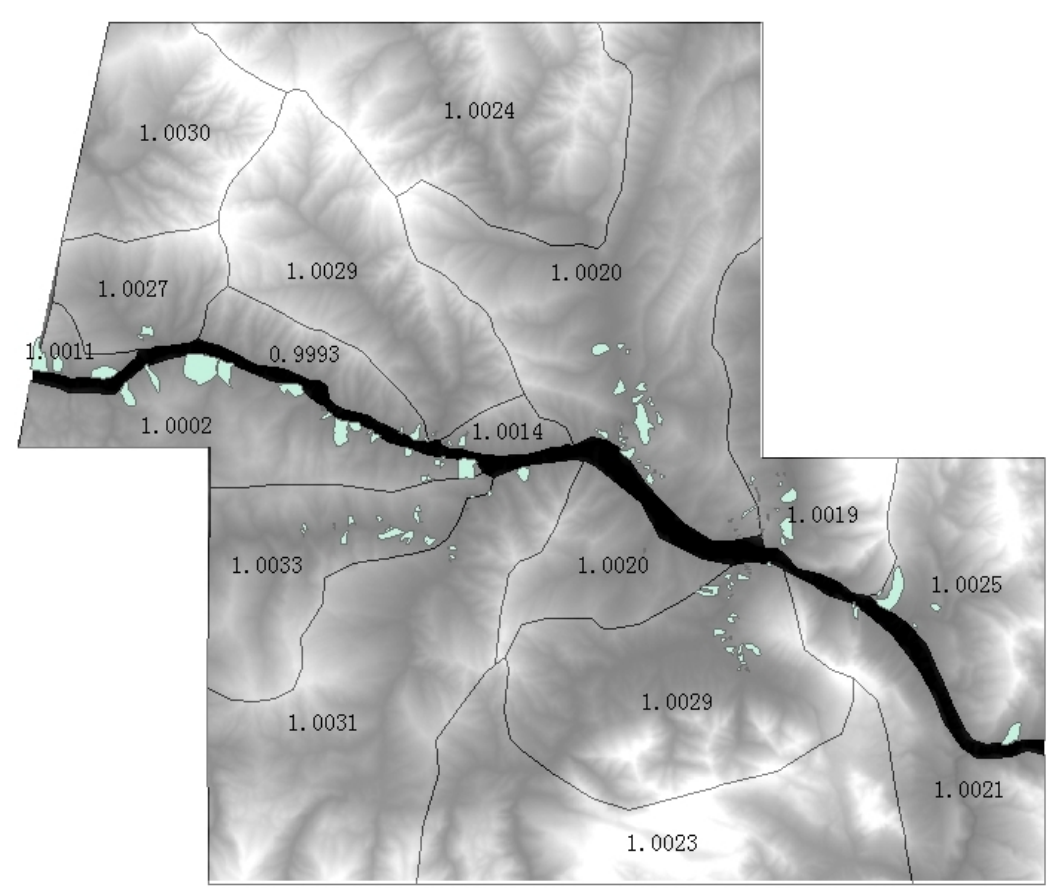

Fig. 3 The fractral dimensions of the river network in the sub-basins of the study area

\section{Conclusions}

Box-counting model can be used to characterize the fractal characteristics of the river network in the landslides area. The data obtained from the study area show power-law distributions of area percentage, shape irregularity, and size-number distribution, and thus reveal some fractal or self-similarity properties. The fractal model provides powerful tools for quantitative description of the river network and the relationship between the river network and the landslides.

\section{Acknowledgements}

This research was financially supported by the National Natural Science Foundation of China (No.51379023), and the Public Welfare Research Project sponsored by Ministry of Water Resources of China (201501033-3).

\section{References}

[1] Wu, S., Shi, L., Wang, R., Tan, C., Hu, D., Mei, Y., Xu, R: Engineering Geology Vol. 59(2001), p. 51.

[2] Mandelbrot B. B.: J. Fluid Mechanics, 1974,62 331

[3] Falconer K, 1990 Fractal Geometry. Wiley, New York, pp 288

[4] Cheng Q 2004 Math. Geology,36 345 